\title{
Decision making on capital markets using trend based research methods
}

\author{
Tomáš Poláček ${ }^{1}$ \\ Brno University of Technology, Faculty of Business and Management \\ Department of Economics, Kolejní 4, 61200 Brno Email: \\ Tomáš Meluzín \\ Brno University of Technology, Faculty of Business and Management \\ Department of Economics, Kolejní 4, 61200 Brno \\ Libor Chládek \\ Brno University of Technology, Faculty of Business and Management \\ Department of Economics, Kolejní 4, 61200 Brno
}

\begin{abstract}
One of the main objectives of this study is to develop a qualitative model that will serve the decision makers' CFOs (chief financial officers), where, as a rule, it is decided without deeper processing of information many factors that affect each other significantly. Lack of appropriate statistical information in connection with turbulently changing environments suggests that further research is needed to extend existing IPO models based on statistical analyzes. The paper is using basic qualitative research of trends. All pairs of relationships are based on trends, either increasing, constant, or decreasing. The key input of the correct IPO timing analysis is based on the knowledge of experts traced from qualitative heuristics. The transition graph is a qualitative interpretation of all possible quantitative time series of all variables used in our IPO timetable and should be used as an effective tool to support CFO decisions.
\end{abstract}

Keywords: Forecast, IPO; Capital markets; Trend; Qualitative; Bankruptcy; Transition;.

JEL Classification: G33, G34

\section{Statement of the problem}

In this study, is intend to offer a different point of view on decision making within the Initial public offering. Where there is no adequate statistical data or shortness of implying any mathematical function for sharp variables on IPO timing, is in this paper given solution by developing a qualitative model supporting chief financial officers (CFOs) when considering going public under conditions of emerging and underdeveloped capital markets. Recent academic theories as well as empirical research documented a wide range of factors that affect decision making on IPO timing in well-developed capital markets. (Lizińska, Czapiewski 2016, Meluzín, Zinecker 2014, Meluzín, Zinecker 2016, Meluzín et al. 2016).

\footnotetext{
${ }^{1}$ Corresponding author
} 
Formal used tools are e.g. : neural networks, genetic algorithms, vague reasoning (fuzzy, qualitative, semi-qualitative, rough, and probabilistic), see e.g. (Fiordaliso, 1998; Punzo, 2003). Numbers and numerical mathematics (e.g. sets of differential equations) are frequently used as well; see e.g. (Lyandresa, Zhdanov, 2013).

This paper deals with IPO forecasting under conditions of severe information shortages. Such IPO are often described by non-numerical quantifiers, e.g. words - low, medium, high. However, the transfer of such verbal values into fuzzy sets is very subjective, see e.g. (Kajal De, 2007; Yi-Chung Hu, Tseng, 2007).

Complexities of real-life bankruptcy tasks make any formal description difficult (Wright, Goodwin, 2009). Sets of input information / knowledge items are extremely heterogeneous, see e.g. (Wright, Goodwin, 2009). The following list gives typical items:

A lack of adequate statistical data sets in connection with turbulently changing environment suggests that an additional research is needed to upgrade and enlarge the established IPO models based on statistical data. This is the reason why information non-intensive formal tools are used more and more frequently, see e.g. fuzzy and / or rough sets (Dočekalová, Kocmanová, 2016; Meluzín et al.)

Therefore, in this study we intend to fill this gap by applying non-numerical on qualitative trends based modelling. Common sense formalization has attracted attention long time ago; see e.g. (Lipmann, Bogen, 1923), (Bredeweg, Salles, 2009). Common sense algorithms based just on four values - positive, zero, negative, anything - are studied in this paper.

\section{Methods - Qualitative Models}

Trend's models are based on shallow knowledge items, e.g. verbal descriptions using linguistic quantification. This is the main reason why simple qualitative shapes/relations are used. All pairwise relations $\mathrm{X}$ and $\mathrm{Y}$ given in Fig. 1 and Fig. 2 are qualitative relations. It means that nothing is quantitatively known.

Six examples of quantifier-less pairwise trend relations are given in the Error! Reference source not found. and Fig. 2. 
Fig. 1: Examples of qualitative direct proportionality pair wise relations

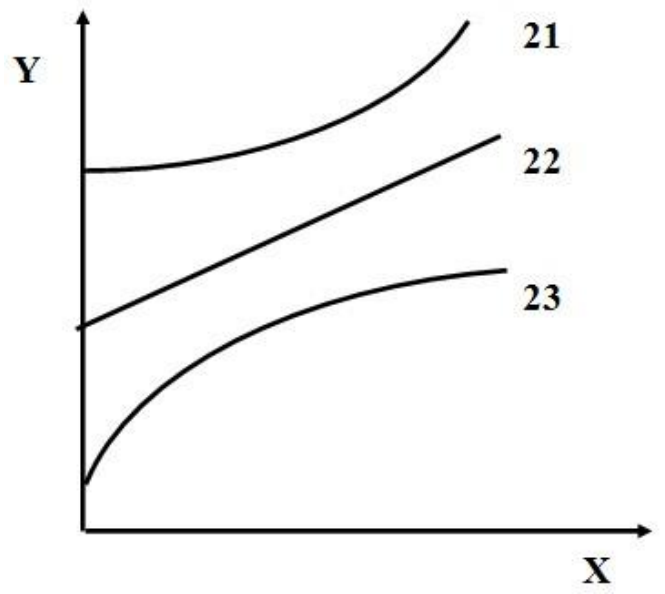

Fig. 2: Examples of qualitative indirect proportionality pair wise relations

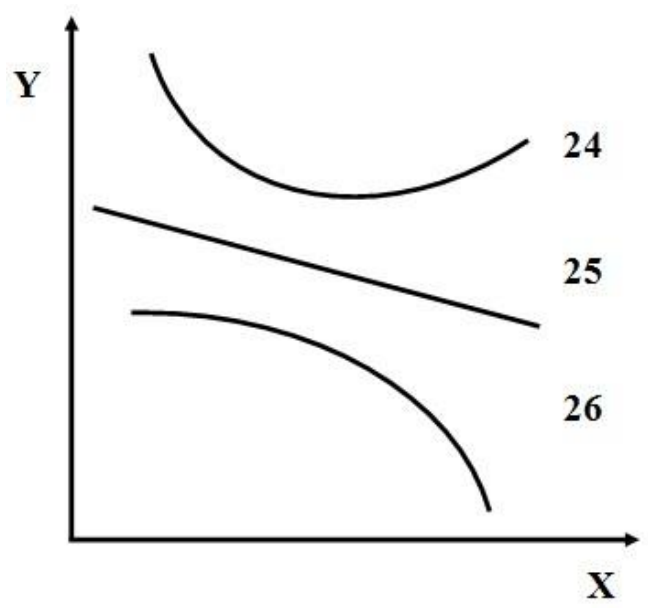

Source: Authors

For example the relation 25 indicates that:

- $\quad$ The relation $\mathrm{Y}=\mathrm{f}(\mathrm{X})$ is decreasing

- There is a linear relationship between $\mathrm{Y}$ and $\mathrm{X}$

- If $\mathrm{X}=0$ then $\mathrm{Y}$ is positive.

There are many different interpretations of trend concepts, see e.g. (Stekler, Symington, 2016; Kamstr, Kennedy, 1998; Kim, Han, 2003). The trend concepts as it is used in this paper is based on four values: see e.g. (Bredeweg, 2009), (Vicha, Dohnal, 2008):

The principal of qualitative modelling consists in the quantifiers as follows:

Positive Zero Negative $\quad$ Any Value 
Where $X_{i}$ is the $i$-th variable and $D X_{i}$ and $D D X_{i}$ are the first qualitative and second qualitative derivations with respect to time $t$. A set $S$ of $m$-qualitative $n$-dimensional scenarios is described by the following set of triplets:

$$
S=\left[\left(X_{1}, D X_{1}, D D X_{1}\right),\left(X_{2}, D X_{2}, D D X_{2}\right), \ldots,(X n, D X n, D D X n)\right] j,
$$

(2) Where $j=1,2, \ldots, m$

The triplet $\left(X_{i}, D X_{i}, D D X_{i}\right)$ is based on the first and second derivative. IPO knowledge is relatively poor and therefore the third derivatives are unknown.

A simple transfer of quantitative derivative $d x_{i} / d t$ to the qualitative derivatives is: if

$$
\begin{gathered}
d x i / d t>0 \text { then } D X i=+ \\
\text { if } d x i / d t=0 \text { then } D X i=0 \\
\text { if } d x i / d t<0 \text { then } D X i=-
\end{gathered}
$$

There are only three qualitative values (1) if the value anything * is ignored. Let us suppose that that all IPO variables are positive

$X_{i}=+; i=1,2, \ldots, n$

For example the Issue size is always positive. The maximum possible number of qualitatively distinguishable scenarios (2) can be evaluated by the following formula:

The order of derivation used in this paper is two, $d=2$. Therefore just the first and second derivatives $D, D D(2)$ are used.

Shallow heuristics are formalised by pairwise relations, see Fig. 1 (Fig. 2). A qualitative model is a set of $w$ pair wise relations:

$$
\begin{aligned}
& P s\left(X_{i}, X_{j}\right) \\
& \text { Where } s=1,2, \ldots, w .
\end{aligned}
$$

Each scenario must be either accepted as a solution of the model (6), or rejected. To simplify the problem let us suppose that all three variables $X_{1}, X_{2}$ and $X_{3}$ are positive as it requires the very nature of IPO. For example, $X_{1}$ is an interest rate and this is always positive. Therefore the following triple is used:

$$
(+, D X 1, D D X 1)
$$

Another simplification is that the second derivatives are ignored or not known. It means that just the following triplet is used $(+, D X 1, *)$, see $(1)$.

If the second derivatives are not known then the model is simplified as follows:

1 If $X_{1}$ is increasing then $X_{2}$ is increasing 
If $X_{1}$ is decreasing then $X_{2}$ is decreasing

(8) 2 If $X_{3}$ is increasing then $X_{2}$ is decreasing

If $X_{3}$ is decreasing then $X_{2}$ is increasing

The model (6) is therefore simplified into the following set of two relations:

DTP $\quad X_{1} X_{2} I T P \quad X_{3} X_{2}$

Where are:

DTP qualitative direct proportionality

(10) ITP qualitative indirect proportionality

DTP covers all three increasing shapes; see no. 21, 22 and 23, Fig. 1

ITP covers all three decreasing shapes; see no. 24, 25 and 26, Fig. 1

Qualitative proportionalities (10) are knowledge items requiring the lowest level of information. Two variables cannot be related by a qualitative proportionality only in the case when nothing is known about their relationship.

\section{Transitional Graphs}

The set of scenarios is not the only result of a trend modelling. It is possible to generate transitions among the set of scenarios.

Fig. 3 A trend description of a quantitative oscillation

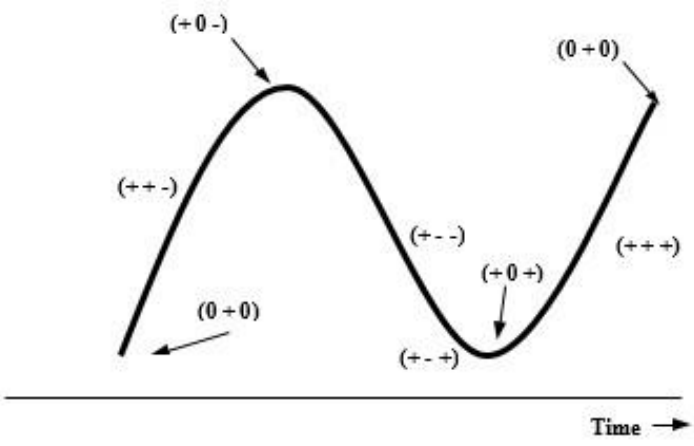

own

Source:

The triplets given in Fig. 3 describe a broad spectrum of different oscillations, e.g. dumped oscillation or irregular oscillations with randomly or deterministically changing frequencies and / or amplitudes.

Any quantitative one-dimensional oscillation, see e.g. Fig. 1 and Fig. 2, can be represented by a simple oriented graph, see Fig. 4. There are 8 one-dimensional scenarios, $m=8, n=1$ (2). Any forecasting related to the oscillation Fig. 1 (Fig. 2) is trivial. For example the scenario (++ -) is transferred into the scenario $(+0-)$, see Fig. 4. 
Fig. 4 Transitional one-dimensional graph of an oscillation, see Tab. 1

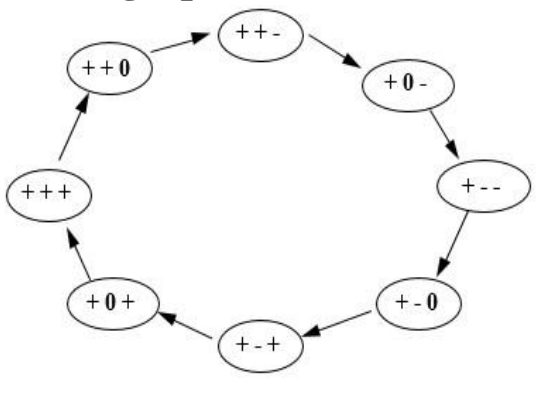

own

Source:

An example of a more complex transitional graph is given in Fig. 5 . There are 5 scenarios, $m=$ 5 (2). The transitional graph in Fig. 5 is an example of an unsteady state behaviour of a more complex model (6).

If a forecaster accepts the model (6), then the corresponding transitional graph represents all possible trend forecasts and all possible trend histories to choose from; no feasible forecast can be overlooked / ignored. It means that the transitional graph is a generator of trend-based forecasts.

Fig. 5 - Transitional graph based on the set of 5 scenarios

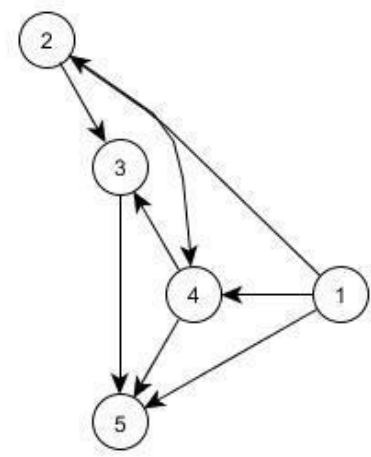

Source: own

Let us suppose that the scenario No. 4 is under study as a current forecasting root. The following paths are two-steps forecasts:

$\mathrm{S}_{4} \rightarrow \mathrm{S}_{3} \rightarrow \mathrm{S}_{5}$

$\mathrm{S}_{4} \rightarrow \mathrm{S}_{2} \rightarrow \mathrm{S}_{3}$

No other two steps behaviours / forecasts are possible.

The complete description of all past two steps histories is given in (11), if the current root is again the scenario No. 4, see Fig. 5.

$\mathrm{S}_{1} \rightarrow \mathrm{S}_{2} \rightarrow \mathrm{S}_{4}$ 
The set $\mathbf{X}$ of variables

$$
\begin{aligned}
& \boldsymbol{X}=X_{1}, X_{2}, \ldots, X_{\mathrm{n}} \quad=(\mathbf{V} \cup \mathbf{G} \cup \mathbf{O}) \\
& \mathbf{V} \cap \mathbf{O}=\emptyset \\
& \mathbf{V} \cap \mathbf{G}=\emptyset \\
& \mathbf{O} \cap \mathbf{G}=\emptyset \\
& \mathbf{V}=\left(\mathrm{V}_{1}, \ldots, \mathrm{V}_{v}\right)=\left(X_{1}, \ldots, X_{v}\right) \\
& \mathbf{G}=\left(\mathrm{G}_{1}, \ldots, \mathrm{G}_{t}\right)=\left(X_{v+1}, \ldots, X_{t}\right) \\
& \mathbf{O}=\left(\mathrm{O}_{1}, \ldots, \mathrm{O}_{w}\right)=\left(X_{t+1}, \ldots, X_{n}\right) \\
& n=v+w+t,
\end{aligned}
$$

is chosen as relevant. Any forecasting / decision-making will be based on a $n$-dimensional model $\mathbf{M}(\mathbf{X})$. A set $\mathbf{X}$ of $n$ variables is a union of Decision variables $\mathbf{V}$, Goals variables $\mathbf{G}$ and Offcontrol variables $\mathbf{O}$ (13).

The set $\mathbf{O}$ of variables is not under control of a forecaster / decision maker. If a forecaster is a company's manager or a government then the set $\mathbf{O}$ is different. This is the reason why future unsteady state behaviours depend heavily on interpretations of the set of variables $\mathbf{X}$ (13).

An example of variables $\mathrm{X}$ presented from the point of view of a company management is:

$\begin{array}{rrr}\text { Recognisability } & \text { V Liquidity risk } & \text { G } \\ \text { Political situation } & \text { O }\end{array}$

The variable $\mathrm{O}$ is controlled by a government and not by a company management.

\section{Confrontations of Models}

It is a well-known fact that bankruptcy models' accuracies are often very low. It is therefore highly desirable to confront results of several models developed by several forecasters / decision makers.

A team of $r$ experts is involved

$$
\mathrm{E}_{1}, \mathrm{E}_{2}, \ldots \mathrm{E}_{\mathrm{r}}
$$


It is usually not possible to achieve a consensus among a team of $r$ forecasters. This is the reason why each forecaster has his/her $\mathrm{n}$-dimensional model:

$$
\mathrm{M}(\mathrm{n})_{1}, \mathrm{M}(\mathrm{n})_{2}, \ldots \mathrm{M}(\mathrm{n})_{\mathrm{r}}
$$

The models (15) are solved and sets of trend n-dimensional scenarios $\mathbf{S}$ are obtained:

$$
\mathrm{S}(\mathrm{n})_{1}, \mathrm{~S}(\mathrm{n})_{2}, \ldots \mathrm{S}(\mathrm{n})_{\mathrm{r}}
$$

$\mathrm{S}(\mathrm{n})_{1}, \mathrm{~S}(\mathrm{n})_{2}, \ldots \mathrm{S}(\mathrm{n})_{\mathrm{r}}$

The Core and Envelope sets of scenarios (16) are, see e.g. (Dohnal, Doubravský, 2015):

$$
\begin{aligned}
& \mathrm{S}_{\mathrm{COR}}(\mathrm{n})=\mathrm{S}(\mathrm{n})_{1} \cap \mathrm{S}(\mathrm{n})_{2}, \ldots \cap \mathrm{S}(\mathrm{n})_{\mathrm{r}} \\
& \mathrm{S}_{\mathrm{ENV}}(\mathrm{n})=\mathrm{S}(\mathrm{n})_{1} \cup \mathrm{S}(\mathrm{n})_{2}, \ldots \cup \mathrm{S}(\mathrm{n})_{\mathrm{r}}
\end{aligned}
$$

The set $S_{C O R}$ eliminates all atypical scenarios and $S_{\text {ENV }}$ covers all possible scenarios generated by all decision makers. It is obvious that $S_{E N V}(n)$ is a superset of $S_{C O R}(n)$ :

$\operatorname{SENV}(\mathrm{n}) \supseteq \operatorname{SCOR}(\mathrm{n})$

\section{Case Study}

A team of two experts was contacted and the list of case study variables was generated:

$\begin{array}{lll}\text { Market condition } & M C D & \mathrm{O} \\ \text { Competition } & C O M & \mathrm{O} \\ \text { Political situation } & P O L & \mathrm{O} \\ \text { Firm size } & F R S & \mathrm{~V} \\ \text { Recognisability } & R E C & \mathrm{~V} \\ \text { The Firm location } & F R L & \mathrm{~V} \\ \text { Issue size } & I S S & \mathrm{G} \\ \text { Liquidity risk } & L Q R & \mathrm{G}\end{array}$

The very nature of the variables (17) indicates that they are difficult to quantify, see e.g. Recognisability.

Let us suppose that there is a team of experts / forecasters, 
$\mathrm{E}_{1}$ and $\mathrm{E}_{2}$,

The first expert $\mathrm{E}_{1}$ developed the following model:

$\begin{array}{llll}1 & 21 & \text { MCD COM } \\ 2 & \text { DTP } & \text { MCD POL } \\ 3 & \text { ITP } & \text { COM FRS } \\ 4 & 21 & \text { COM LQR } \\ 5 & 25 & \text { COM ISS } \\ 6 & \text { DTP } & \text { POL } & \text { FRL } \\ 7 & \text { DTP } & \text { FRS } & \text { ISS } \\ 8 & \text { ITP } & \text { REC } & \text { LQR }\end{array}$

There are 17 scenarios; $\mathrm{m}=17$

\begin{tabular}{|c|c|c|c|c|c|c|c|c|c|c|c|c|}
\hline \multirow[t]{2}{*}{ \# } & \multicolumn{3}{|c|}{ MCD COM POL } & FRS & REC & FRL & ISS & LQR & & & & \\
\hline & $\mathrm{O}$ & $\mathrm{O}$ & $\mathrm{O}$ & V & V & V & $\mathrm{G}$ & $\mathrm{G}$ & & & & \\
\hline 1 & +++ & +++ & +++ & +- & +-- & +++ & +-- & +++ & & & & \\
\hline 2 & ++0 & +++ & ++0 & +- & +-- & ++0 & +- & +++ & & & & \\
\hline 3 & ++- & +++ & ++- & +-- & +-- & ++- & +-- & +++ & & & & \\
\hline 4 & ++- & ++0 & ++- & +-0 & +-- & ++- & +-0 & +++ & & & & \\
\hline 5 & ++- & $\begin{array}{l}++- \\
+-0\end{array}$ & $\begin{array}{l}++- \\
++-\end{array}$ & $\begin{array}{l}+-+ \\
+-+\end{array}$ & $\begin{array}{l}+-+ \\
++0\end{array}$ & ++- & +-+ & ++-6 & ++- & ++- & ++- & +-+ \\
\hline 7 & ++- & ++- & ++- & +-+ & +-- & ++- & +-+ & +++ & & & & \\
\hline 8 & $+0+$ & $+0+$ & $+0+$ & $+0-$ & $+0-$ & $+0+$ & $+0-$ & $+0+$ & $(23)$ & & & \\
\hline 9 & +00 & +00 & +00 & +00 & +00 & +00 & +00 & +00 & & & & \\
\hline 10 & +0 & $+0-+0-$ & $+0+$ & $+0++0$ & $+0+$ & $+0-11$ & +-++- & ++-+ & ++- ++- & -+-+ & ++-+-+ & \\
\hline 12 & +-0 & +-+ & +-0 & ++- & ++- & +-0 & ++- & +-+ & & & & \\
\hline 13 & +-- & +-+ & +-- & ++- & ++- & +-- & ++- & +-+ & & & & \\
\hline 14 & +-- & +-0 & +-- & ++0 & ++- & +-- & ++0 & +-+ & & & & \\
\hline 15 & +-- & $\begin{array}{l}+-- \\
++0\end{array}$ & $\begin{array}{l}+-- \\
+--\end{array}$ & $\begin{array}{l}+++ \\
+++\end{array}$ & $\begin{array}{l}+++ \\
+-0\end{array}$ & +-- & +++ & +-16 & $5+-$ & +-- & +-- & +++ \\
\hline 17 & +-- & +-- & +-- & +++ & ++- & +-- & +++ & +-+ & & & & \\
\hline
\end{tabular}

There are 41 possible transitions among 17 scenarios (23). The transitional graph is very complex, see Fig. 6. 
Fig. 6 - Transitional graph based on the set of 17 scenarios (23)

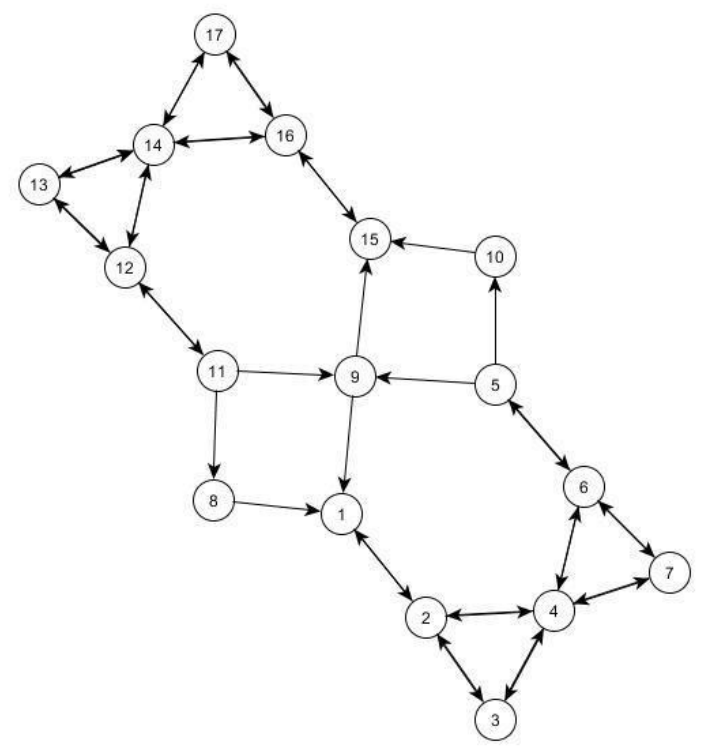

The second expert $\mathrm{E}_{2}$ (14) modified the model of the first expert. The following relation:

$\begin{array}{llll}6 & 24 & \text { POL } & \text { LQR } \\ 9 & 22 & \text { REC } & \text { ISS }\end{array}$

was used.

Therefore the model of the second expert is:

$\begin{array}{llll}1 & 21 & \text { MCD COM } \\ 2 & \text { ITP } & \text { COM FRS } \\ 3 & 21 & \text { COM LQR } \\ 4 & 25 & \text { COM ISS } \\ 5 & \text { DTP } & \text { POL } & \text { FRL } \\ & & & \\ 6 & 24 & \text { POL } & \text { LQR } \\ 7 & \text { DTP } & \text { FRS } & \text { ISS } \\ 8 & \text { ITP } & \text { REC } & \text { LQR } \\ 9 & 22 & \text { REC } & \text { ISS }\end{array}$

There are 23 scenarios; $m=23$

$\begin{array}{lllllllll}\# & \text { MCD } & \text { COM } & \text { POL } & \text { FRS } & \text { REC } & \text { FRL } & \text { ISS } & \text { LQR } \\ & \mathrm{O} & \mathrm{O} & \mathrm{O} & \mathrm{V} & \mathrm{V} & \mathrm{V} & \mathrm{G} & \mathrm{G} \\ 1 & +++ & +++ & +-+ & +-- & +-- & +-+ & +- & +++ \\ 2 & +++ & +++ & +-0 & +-- & +-- & +-0 & +-- & +++ \\ 3 & +++ & +++ & +-- & +-- & +-- & +- & +-- & +++ \\ 4 & ++0 & +++ & +-+ & +-- & +-- & +-+ & +- & +++ \\ 5 & ++0 & +++ & +-0 & +-- & +-- & +-0 & +-- & +++ \\ 6 & ++0 & +++ & +-- & +-- & +-- & +-- & +- & +++\end{array}$




$\begin{array}{lllllllll}7 & ++- & +++ & +-+ & +-- & +-- & +-+ & +- & +++ \\ 8 & ++- & +++ & +-0 & +- & +-- & +-0 & +- & +++ \\ 9 & ++- & +++ & +-- & +- & +-- & +- & +- & +++ \\ 10 & ++- & ++- & +-+ & +-+ & +-+ & +-+ & +-+ & ++- \\ 11 & +0+ & +0+ & +0- & +0- & +0- & +0- & +0- & +0+ \\ 12 & +00 & +00 & +00 & +00 & +00 & +00 & +00 & +00\end{array}$

$13+0-+0-+0++0++0++0++0++0-14+-++-++++++-$ ++- +++ ++- +-+

$\begin{array}{lllllllll}15 & +-+ & +-+ & ++0 & ++- & ++- & ++0 & ++- & +-+ \\ 16 & +-+ & +-+ & ++- & ++- & ++- & ++- & ++- & +-+ \\ 17 & +-0 & +-+ & +++ & ++- & ++- & +++ & ++- & +-+ \\ 18 & +-0 & +-+ & ++0 & ++- & ++- & ++0 & ++- & +-+ \\ 19 & +-0 & +-+ & ++- & ++- & ++- & ++- & ++- & +-+ \\ 20 & +- & +-+ & +++ & ++- & ++- & +++ & ++- & +-+ \\ 21 & +-- & +-+ & ++0 & ++- & ++- & ++0 & ++- & +-+ \\ 22 & +- & +-+ & ++- & ++- & ++- & ++- & ++- & +-+ \\ 23 & +- & +- & +++ & +++ & +++ & +++ & +++ & +-\end{array}$

Fig. 7 - Transitional graph based on the set of 23 scenarios (25)

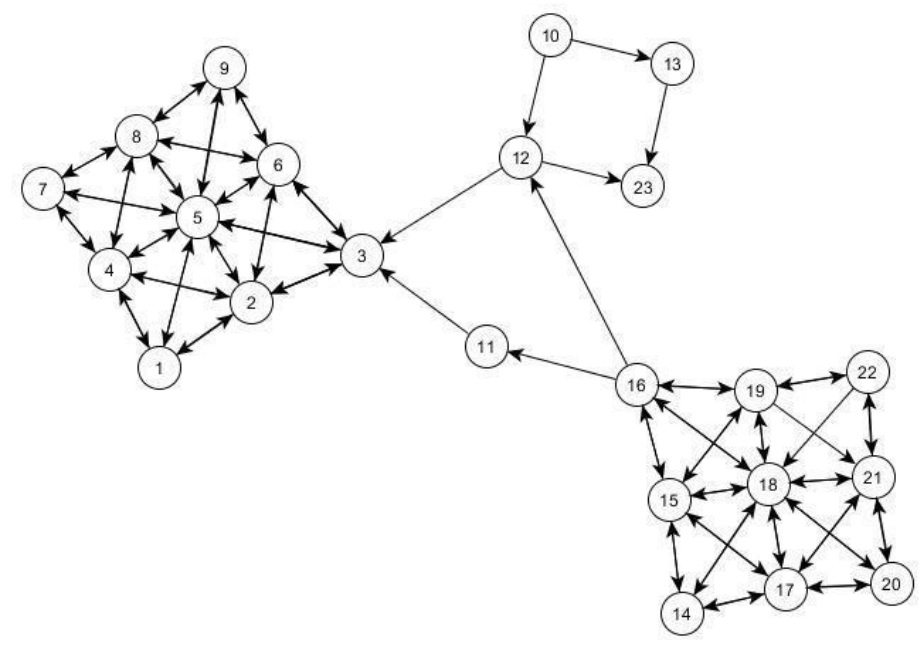

Both models (22)(24) are heavily subjective. An elimination of atypical scenarios is therefore desirable. An unification (see the Envelope (18)) of the sets of scenarios (23)(25) includes all the options that have been changed by both experts. The unification has 27 scenarios, see (26).

There are 27 scenarios; $\mathrm{m}=27$

$\begin{array}{lllllllll}\# & \text { MCD } & \text { COM } & \text { POL } & \text { FRS } & \text { REC } & \text { FRL } & \text { ISS } & \text { LQR } \\ & \text { O } & \text { O } & \text { O } & \text { V } & \text { V } & \text { V } & \text { G } & \text { G } \\ 1 & +++ & +++ & +++ & +-- & +- & +++ & +- & +++ \\ 2 & ++0 & +++ & ++0 & +-- & +- & ++0 & +- & +++ \\ 3 & ++- & +++ & ++- & +-- & +- & ++- & +- & +++ \\ 4 & ++- & ++0 & ++- & +-0 & +- & ++- & +-0 & +++ \\ 5 & ++- & ++- & ++- & +-+ & +-+ & ++- & +-+ & ++-6 \\ & & ++- & ++- & ++- & +-+ & +-0 & ++- & +-+ \\ & & ++0 & & & & & & \\ 7 & ++- & ++- & ++- & +-+ & +- & ++- & +-+ & +++\end{array}$


$8 \quad+0+\quad+0+\quad+0+\quad+0-\quad+0-\quad+0+\quad+0-\quad+0+$

$9+0-+0-+0-+0++0++0-+0++0-10+-++-++-+++-++-$ $+-+++-+-+$

$\begin{array}{lllllllll}11 & +-0 & +-+ & +-0 & ++- & ++- & +-0 & ++- & +-+\end{array}$

$12 \quad+--\quad+-+\quad+--\quad++-\quad++-\quad+--\quad++-\quad+-+$

$13 \quad+--\quad+-0 \quad+--\quad++0 \quad++-\quad+--\quad++0 \quad+-+$

$14 \quad+--\quad+--\quad+--\quad+++\quad+++\quad+--\quad+++\quad+-$

(26)

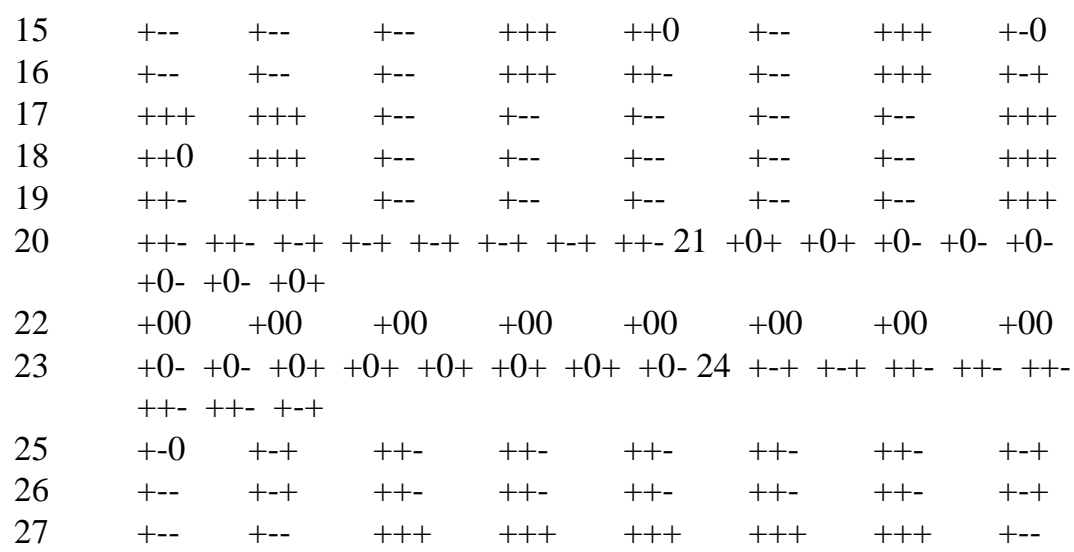

Fig. 8 - United transitional graph based on the set of 27 scenarios (26)

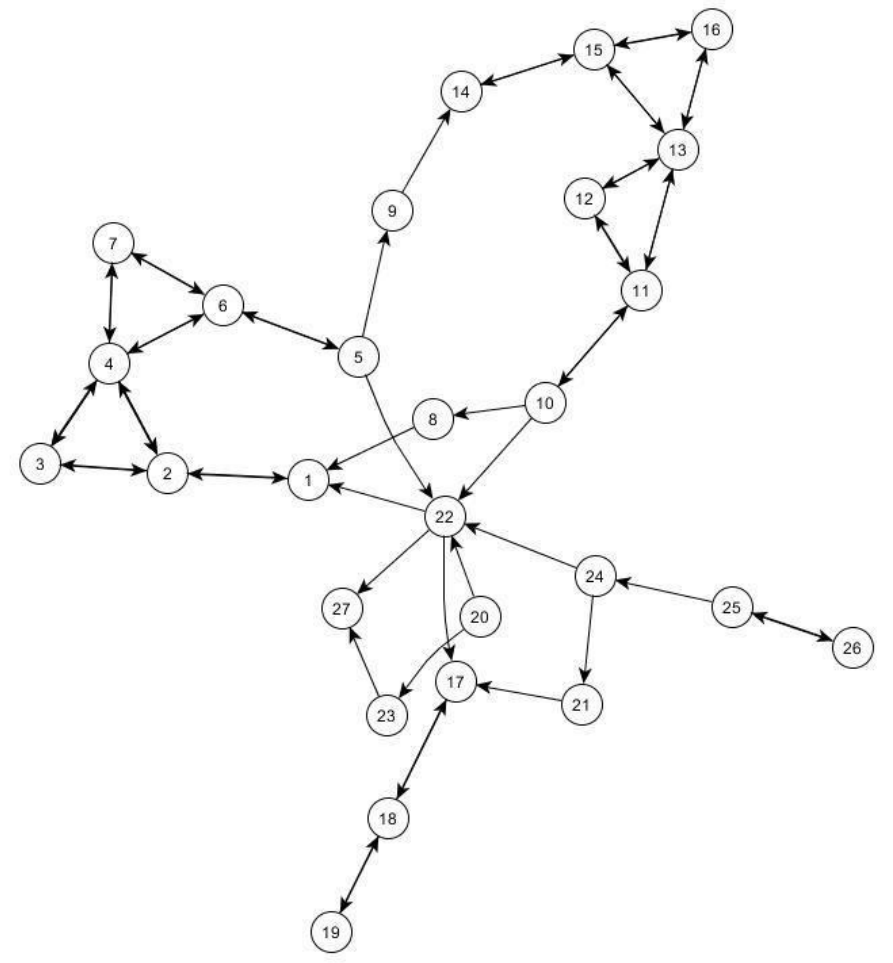

Any prediction is heavily predetermined by interpretations of variables (20). The choice of the sets $\mathbf{V}, \mathbf{O}, \mathbf{G}$, is of crucial importance and is based on the current point of view. Let us suppose that the following interpretations of variables are done from the point of view of a CFO:

It means that, see (11): 
$\mathbf{O}=[\mathrm{MCD}, \mathrm{COM}, \mathrm{POL}]$

$\mathbf{G}=[\mathrm{ISS}, \mathrm{LQR}]$

$=[\mathrm{FRS}, \mathrm{REC}, \mathrm{FRL}]$

The worst trend description of the CFO's view is:

LQR Increase more and more rapidly

$\mathrm{DLQR}=+\quad$ DDLQR $=+$

ISS Decreasing more and more rapidly

DISS $=-\quad$ DDISS $=-$

The following study is focused on the successful enter on capital market and optimal issue of emission from the CFO's point of view.

Let the current situation is the worst possible, see (28). The start-up scenario will be based on the current status of the entity

The target scenario $\mathrm{S}_{\text {Target }}$ is the scenario No. 27; see which represents the best possible creditor variant / scenario.

$\mathrm{S}_{\text {Target }}=\mathrm{S}_{27}$

Fig. 9 - Trend tree of all paths to reach the target scenario $S_{27}$

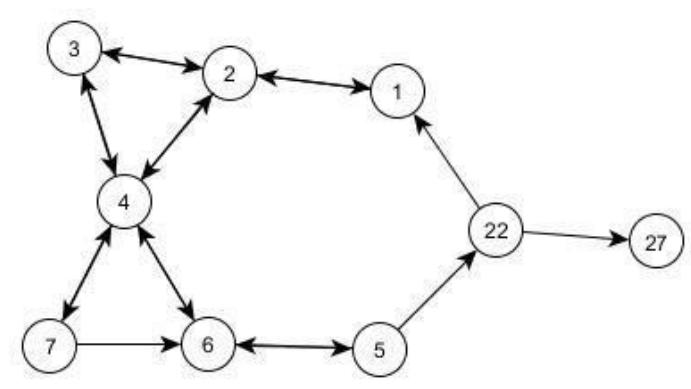

The shortest path is the path leading from the worst scenario $S_{1}$ to the target scenario $S_{27}$; see e.g. Fig. 9:

$$
\mathrm{S}_{1} \rightarrow \mathrm{S}_{2} \rightarrow \mathrm{S}_{4} \rightarrow \mathrm{S}_{6} \rightarrow \mathrm{S}_{5} \rightarrow \mathrm{S}_{22} \rightarrow \mathrm{S}_{27}
$$

The sequence of scenarios is, see (30):

\begin{tabular}{lllllllll}
$\#$ & \multicolumn{2}{c}{ MCD COM POL } & FRS & REC & FRL & ISS & LQR \\
& $\mathrm{O}$ & $\mathrm{O}$ & $\mathrm{O}$ & $\mathrm{V}$ & $\mathrm{V}$ & $\mathrm{V}$ & $\mathrm{G}$ & $\mathrm{G}$ \\
1 & +++ & +++ & +++ & +-- & +-- & +++ & +-- & +++ \\
2 & ++0 & +++ & ++0 & +-- & +-- & ++0 & +- & +++
\end{tabular}




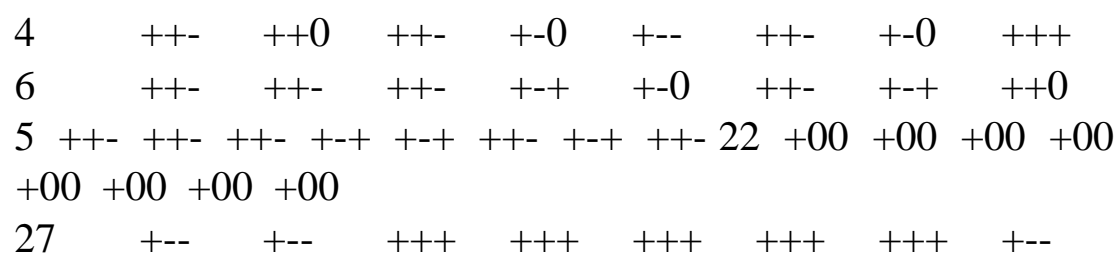

A decision maker, in this case CFO, has no free choice to change the variables (20). Some variables are not under his/her control (27). Therefore, there are variables selected by $\mathbf{O}$ as out of control. It means that any forecast is partially based on available descriptions of $\mathbf{O}$ variables (13) e.g. probability distributions.

\section{Conclusion}

At present, most of the techniques used for various analyses of entering on capital markets problems are of analytical and/or statistical natures. As a matter of fact these precise mathematical tools do not always contribute as much as is expected towards a full understanding of such tasks.

The main advantage of a qualitative IPO analysis is that no numerical values of constants and parameters are needed and the set of qualitative solutions is a superset of all meaningful scenarios, i.e. forecasts. No reasonable forecast can be missed if the analysis is based on a good qualitative model.

A decision maker requires transparent and easy to understand explanations why different algorithms generate some forecast. If formal tools are mathematically too demanding then it is very difficult to introduce them into the BI community. Qualitative models are difficult to solve but easy to interpret.

There are several unsolved problems of qualitative modelling and therefore results of qualitative approximations of some qualitative models can be problematic. If there is no scenario, $\mathrm{m}=0$ (9), then the studied model itself is not consistent. If there is no scenario then it is a reliable indication that a mistake was made in process of model developing meaning the variables are at some point in contradiction.

It is very probable that developments of relevant formal tools of artificial intelligence will have important consequences. Naïve physics and consequently algorithms based on common sense reasoning will be used in IPO models and related tasks more and more extensively.

In conclusion, the choice of variables for the behaviour of the model is a purely subjective opinion of the authors with the help of experts in the field.

\section{Acknowledgements}

This paper was supported by grants FP-J-18-4914 "Decisions on entering the capital markets using qualitative modelling methods."

\section{References}


Bredeweg, B., Salles, P., 2009. Qualitative models of ecological systems - Editorial introduction. Ecol. Inform., Special Issue: Qualitative models of ecological systems 4, 261262. doi:10.1016/j.ecoinf.2009.10.001

Dočekalová, M.P., Kocmanová, A., 2016. Composite indicator for measuring corporate sustainability. Ecol. Indic. 61, Part 2, 612-623. doi:10.1016/j.ecolind.2015.10.012

Dohnal, M., Doubravsky K., Qualitative Upper and Lower Approximations of Complex Nonlinear Chaotic and Non-chaotic Models, International Journal of Bifurcation and Chaos, Volume 25, Issue 13, 15 December 2015

Chaudhuri Kajal De, Fuzzy Support Vector Machine for bankruptcy prediction, Applied Soft Computing, Volume 11, Issue 2, March 2011, Pages 2472-2486

Kamstr M., Kennedy P., Combining qualitative forecasts using logit, International Journal of Forecasting 14 (1998) 83-93

Lipmann, O. Bogen, H. Naive Physik: Arbeiten aus dem Institut für Angewandte Psychologie in Berlin; theoretische und experimentelle Untersuchungen über die Fähigkeit zu intelligentem Handeln. Leipzig: Johann Ambrosius Barth, 1923.

Lyandresa E., Zhdanov A., Investment opportunities and bankruptcy prediction, Journal of Financial Markets 16 (2013) 439 - 476

Meluzín, T., M. Zinecker a N. Lace. Going Public: Key Factors to Consider by IPO Candidates on Emerging Markets of Poland and the Czech Republic. Engineering Economics, 2016, vol. 27, no. 4, p. 392-404. ISSN 1392-2785.

Meluzín, T. a M. Zinecker. Trends in IPOs: The Evidence from CEE Capital Markets. Equilibrium - Quarterly Journal of Economics and Economic Policy, 2016, vol. 11, no. 2, p. 327-341. ISSN 1689-765X.

Orrell, D., McSharry, P., 2009. System economics: Overcoming the pitfalls of forecasting models via a multidisciplinary approach. Int. J. Forecast., Special section: Decision making and planning under low levels of predictability 25, 734-743. doi:10.1016/j.ijforecast.2009.05.002

Punzo, L.F., 2003. Some new tools for the qualitative analysis of dynamic economic data: symbolic and distribution analyses for multi-regime dynamics. Struct. Change Econ. Dyn. 14, 121-131. doi:10.1016/S0954-349X(02)00049-8

Stekler H., Hilary Symington H., Evaluating qualitative forecasts: The FOMC minutes, 20062010, International Journal of Forecasting, International Journal of Forecasting 32 (2016) 559570

Vicha, T., Dohnal, M., 2008. Qualitative identification of chaotic systems behaviours. Chaos Solitons Fractals 38, 70-78. doi:10.1016/j.chaos.2008.01.027

Wright G., Goodwin P., Decision making and planning under low levels of predictability: Enhancing the scenario method, International Journal of Forecasting 25 (2009) 813-825

Yi-Chung $\mathrm{Hu}$, Fang-Mei Tseng, Functional-link net with fuzzy integral for bankruptcy prediction, Neurocomputing, Volume 70 Issue 16-18, October, 2007, Pages 2959-2968 